Fetal Diagnosis

and Therapy

\title{
Effect of Anesthesia on the Developing Brain: Infant and Fetus
}

\author{
Dean B. Andropoulos
}

Texas Children's Hospital, and Department of Anesthesiology, Baylor College of Medicine, Houston, TX, USA

\section{Keywords}

Anesthetic neurotoxicity · Neonate $\cdot$ Fetus .

Dexmedetomidine $\cdot$ Isoflurane $\cdot$ Sevoflurane

\section{Abstract}

The potential for commonly used anesthetics and sedatives to cause neuroapoptosis and other neurodegenerative changes in the developing mammalian brain has become evident in animal studies over the past 15 years. This concern has led to a number of retrospective studies in human infants and young children, and some of these studies observed an association between exposure to general anesthesia as an infant, and later neurobehavioral problems in childhood. This association is particularly evident for prolonged or repeated exposures. Because of the significant growth of fetal interventions requiring sedation and analgesia for the fetus, or because of maternal anesthetic effects, this concern about anesthetic neurotoxicity is relevant for the fetus. The potential for anesthetic neurotoxicity is the most important clinical and research problem in the field of pediatric anesthesiology. This review will first briefly summarize the rapid brain growth and development in the fetus and neonate. Next, animal model data of anesthetic neurotoxicity in the fetus and neonate will be presented, followed by a review of

\section{KARGER}

(C) 2017 S. Karger AG, Basel

E-Mail karger@karger.com

www.karger.com/fdt recent human clinical anesthetic neurotoxicity trials. Finally, the rationale for studying dexmedetomidine as a potential neuroprotectant agent in anesthetic neurotoxicity will be reviewed along with study design for two human clinical trials involving dexmedetomidine.

(c) 2017 S. Karger AG, Basel

\section{Introduction}

The potential for commonly used anesthetics and sedatives to cause neuroapoptosis and other neurodegenerative changes in the developing mammalian brain has become evident in animal studies over the past 15 years [15]. This concern has led to a number of retrospective studies in human infants and young children, and some of these studies observed an association between exposure to general anesthesia as an infant, and later neurobehavioral problems in childhood $[6,7]$. This association is particularly evident for prolonged or repeated exposures. Because of the significant growth of fetal interventions requiring sedation and analgesia for the fetus, or because of maternal anesthetic effects, this concern about anesthetic neurotoxicity is relevant for the fetus. The potential for anesthetic neurotoxicity is the most important clinical

Dean B. Andropoulos, MD, MHCM

Department of Anesthesiology, Baylor College of Medicine 6621 Fannin, W 17417

Houston, TX 77030 (USA)

E-Mail dra@bcm.edu 


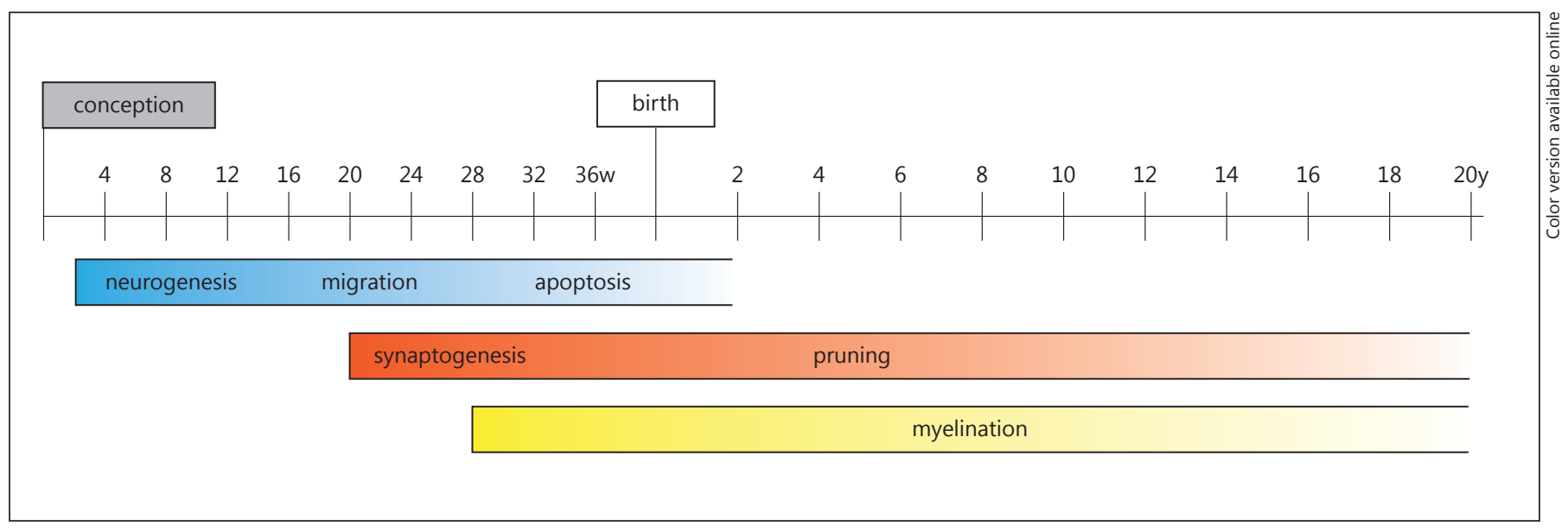

Fig. 1. Timing and intensity of key neurodevelopmental processes in the human brain. Reproduced with permission from Tymofiyeva et al. [13].

and research problem in the field of pediatric anesthesiology [8-12]. This review will first briefly summarize the rapid brain growth and development in the fetus and neonate. Next, animal model data of anesthetic neurotoxicity in the fetus and neonate will be presented, followed by a review of recent human clinical anesthetic neurotoxicity trials. Finally, the rationale for studying dexmedetomidine as a potential neuroprotectant agent in anesthetic neurotoxicity will be reviewed along with study design for two human clinical trials involving dexmedetomidine.

\section{Brain Growth and Development in the Fetus and Neonate}

Neurogenesis begins in the early weeks of gestation after conception, and migration of neurons ensues between 12 and 20 weeks' gestation, after development in the germinal matrix and subventricular zone [13]. The cortical neurons follow a scaffold of glial cells to their final destinations. After migration, neuroapoptosis, or programmed cell death, occurs at a high rate from 24 weeks' gestation to 4 weeks after birth. Another major neurodevelopmental process is the proliferation of neuronal synapses, which begins around the 20th week of gestation and continues rapidly, with synapse number reaching a peak at about $1-2$ years of age with numbers $50 \%$ higher than in the adult. Subsequently, some synapses undergo a process of pruning, where loss of synaptic connections occurs. The fourth major neurodevelopmental process is myelination, which begins by the end of the second trimester and continues at a slower rate throughout childhood. Figure 1 is a graphic depiction of the timing and relative intensity of each of these processes.

Significant advances in magnetic resonance imaging (MRI) techniques as applied to the fetal brain have afforded a window into the complex, rapid development of individual white matter fiber tracts with modification of diffusion tensor imaging (DTI) techniques [14]. DTI describes the behavior and movement of water molecules in the brain with the MRI magnetic field. Sophisticated post-image processing can visualize individual fiber tracts, and computational fiber tractography is then used to delineate the fetal brain connectome. The connectome is the brain's network of neural connections between brain regions, and recent publications have described the arrangement of brain connections, how these connections develop, and the efficiency of these connections. The color-coded images vividly portray the immense number of fiber tracts and the tremendous rapidity with which they develop in the human fetal brain (Fig. 2).

The $\gamma$-aminobutyric acid (GABA) and glutamate neurotransmitter and receptor systems play an important role in neurodevelopment. Not only are these systems fundamental to neuronal connection and communication, but in the absence of neuronal transmission and binding of GABA and glutamate, neurons undergo neuroapoptosis, a process whereby "unneeded" neurons undergo cell death [15]. Neuroapoptosis is a natural process that affects as many as $1 \%$ of neurons per day at its peak period late in gestation and early in postnatal life [16]. $\begin{array}{ll}2 & \text { Fetal Diagn Ther 2018;43:1-11 } \\ \text { DOI: } 10.1159 / 000475928\end{array}$
Andropoulos 


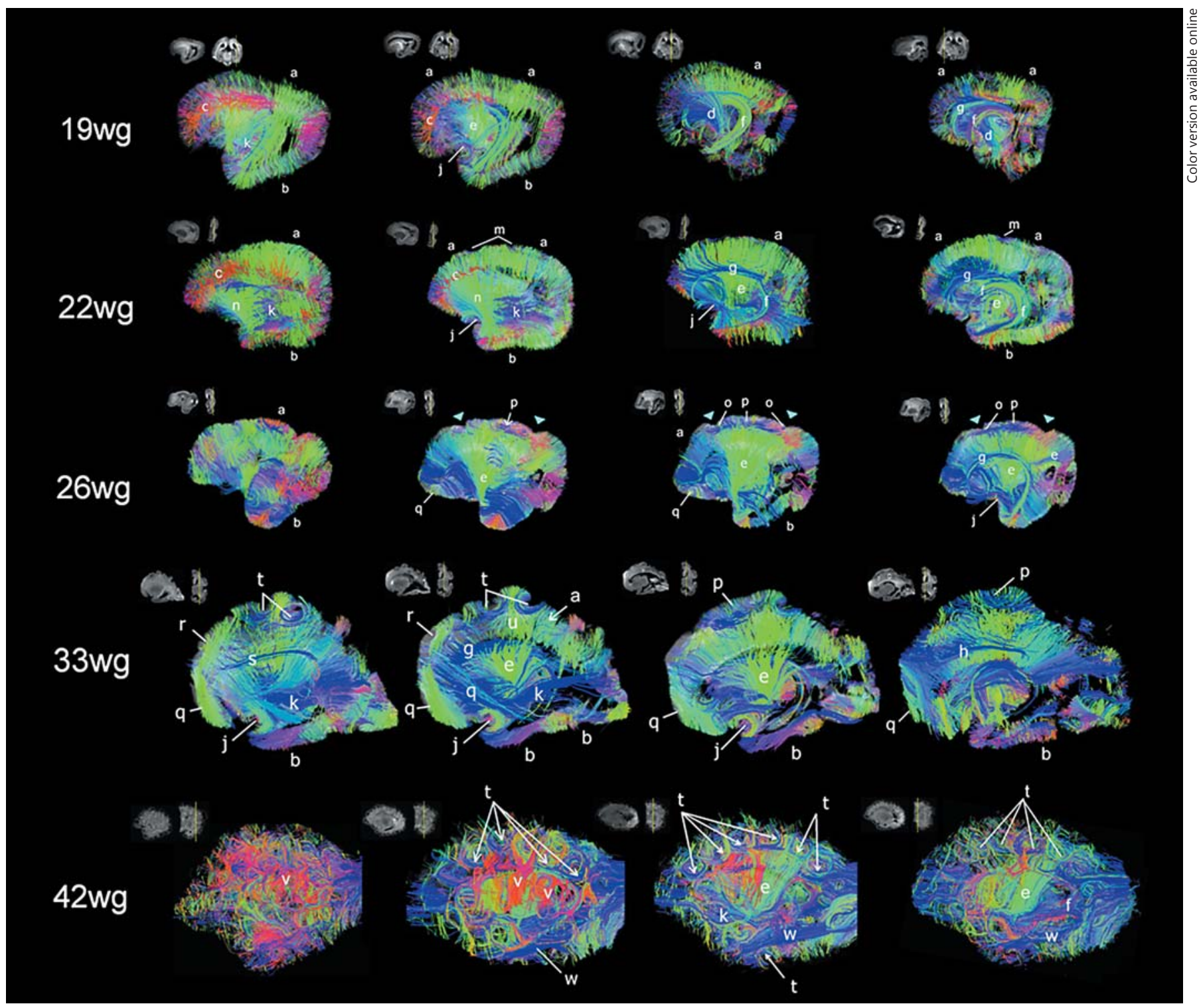

Fig. 2. The fetal brain connectome. Magnetic resonance imaging tractography of the development of individual white matter fiber tracts produced using diffusion tensor imaging, imaged at 10 through 42 weeks of gestation (wg). Note the rapid proliferation of fiber tracts at all gestational ages. Orientation of fiber tracts is color-coded: red - left/right; blue - anterior/posterior; green - dorsal/ ventral orientation. Reproduced with permission from Huang and Vasung [14].
The intense activity surrounding neuroapoptosis and synaptogenesis in the second- and third-trimester fetus reaches its peak during this stage of neurodevelopment, slowing near term and in early postnatal weeks. The effects of anesthetic and sedative agents on synaptogenesis and neuroapoptosis, described below, render the fetal brain particularly sensitive to the effects of these drugs; likely more so than in the neonate and young infant.

Effect of Anesthesia on the Developing Brain

\section{Anesthetic Neurotoxicity in Animal Models of the Developing Brain}

All of the commonly used anesthetic and sedative agent classes bind either to the GABA receptor, or to the $\mathrm{N}$-methyl-D-aspartate receptor (NMDA - a subtype of the glutamate receptor) to produce their anesthetic and sedative effects. GABA-binding agents include volatile anesthetic gases, propofol, benzodiazepines, barbiturates,

Fetal Diagn Ther 2018;43:1-11 DOI: $10.1159 / 000475928$ 
Table 1. Anesthetic, sedative, and analgesic agents and receptor binding

\begin{tabular}{lllll}
\hline Agent & GABA & NMDA & $\mu$-Opioid & $\alpha_{2}$-Adrenergic \\
\hline $\begin{array}{l}\text { Halogenated anesthetics } \\
\quad \text { (sevoflurane, isoflurane, desflurane) }\end{array}$ & + & & \\
Nitrous oxide & & - & \\
Benzodiazepines & + & & \\
Propofol & + & & \\
Barbiturates & + & & \\
Etomidate & + & & \\
Chloral hydrate & + & & \\
Ketamine & & - & + \\
Opioids & & & + \\
Dexmedetomidine & & & \\
\hline
\end{tabular}

GABA, $\gamma$-aminobutyric acid; NMDA, N-methyl-D-aspartate; +, agonist; -, antagonist. Data are from Istaphanous et al. [17].

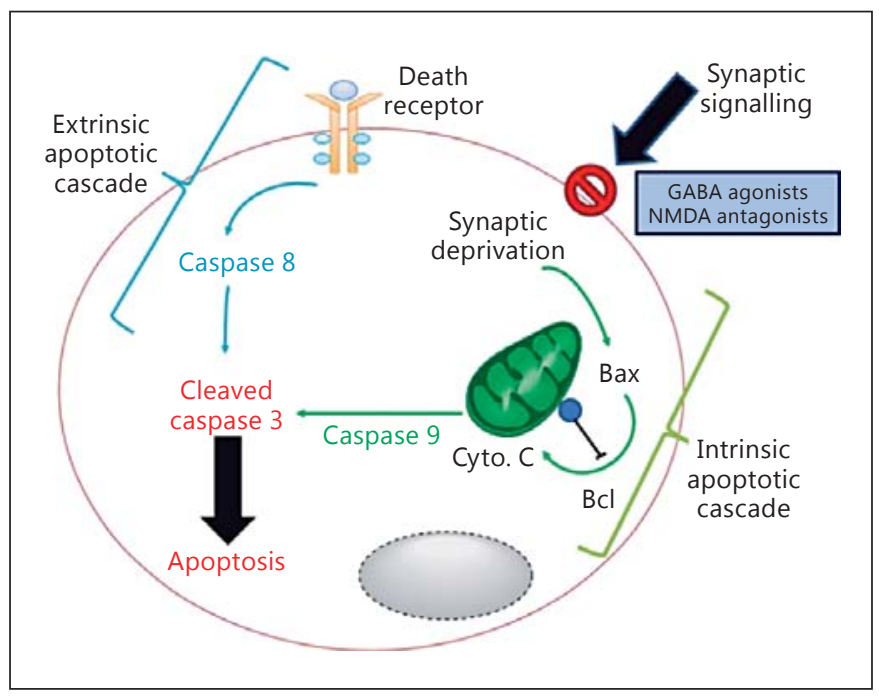

Fig. 3. Proposed mechanism of anesthetic-induced neurodegeneration. See text for details. Reproduced with permission from Sanders et al. [15].

etomidate, and chloral hydrate. NMDA-binding agents include nitrous oxide and ketamine [17] (Table 1). Because of their mechanism of action, and interaction with, and effect on normal neurotransmission, it is plausible to consider that these agents could have effects on neuroapoptosis and synaptogenesis in the rapidly developing immature brain. Indeed, Ikonomidou et al. [2] published a seminal article in 1999 describing a 15- to 40-fold increase in neuroapoptosis in multiple brain regions after exposure to ketamine in P7 neonatal rats. In 2003, Jevtovic-Todorovic et al. [3] exposed neonatal rats to clinical concentrations of nitrous oxide, isoflurane, and midazolam for $6 \mathrm{~h}$ and found a 20- to 60-fold increase in neuroapoptosis in multiple brain regions. In the cohort of survival animals, long-term neurobehavioral deficits in learning, memory, and spatial discrimination were demonstrated. This landmark paper is credited with initiating the intense interest in determining whether human neonates and infants could be affected by the problem of anesthetic neurotoxicity. In the ensuing years, several hundred studies in animal models have been published, and virtually all have replicated the findings of acute neurodegenerative changes and long-term neurobehavioral changes with all common GABA- and NMDA-binding agents [1]. The animal models have extended to non-human primates, determining that exposure to ketamine and volatile anesthetics result in long-term learning problems [4]. A recent study by Coleman et al. [18] exposed neonatal rhesus macaques to $5 \mathrm{~h}$ of isoflurane anesthesia either once or 3 times to test dose-response to multiple exposures. When compared to control animals, neonatal monkeys exposed to isoflurane 3 times had motor reflex deficits at 1 month of age, and increased anxiety behaviors. A single exposure did not affect these parameters. More detailed neurocognitive testing was performed on these animals with the data currently being analyzed.

The proposed mechanism for anesthetic induced neuroapoptosis in the developing brain is depicted in Figure 3. Binding of GABA and NMDA agents blocks normal neurotransmission in the GABA and glutamate systems, resulting in synaptic deprivation [15]. This in turn leads to the activation of the intrinsic neuroapoptotic cascade due to lack of neuronal stimulation. Mitochondrial disruption occurs as part of this process and can be observed Fetal Diagn Ther $2018 ; 43: 1-11$
DOI: $10.1159 / 000475928$
Andropoulos 
in electron microscopic studies of anesthetic exposure. Caspase 9 is released from the mitochondrion, resulting in increased caspase 3 concentrations (standard to measure apoptosis), inciting the completion of the neuroapoptosis process. Other mechanisms for neurodegeneration include decreased dendrite and spine formation and decreased neuronal migration.

In addition to studies of neonatal anesthetic exposure, a number of studies of fetal anesthetic exposure in rodents, sheep, and non-human primates have been published; neuroapoptosis and other neurodegenerative changes are described with fetal exposure to ketamine, propofol, volatile anesthetic agents, barbiturates, and benzodiazepines [19-22].

In spite of the consistent and reproducible results of anesthetic exposure in fetal and neonatal animal models, such models have a number of shortcomings [1]. These include lack of surgical stimulation in all but a few of these studies. This is problematic because the contribution of surgical stress, pain, inflammation, and tissue trauma to neurodegeneration has not been fully elucidated. Untreated pain in animal models also leads to increased neuroapoptosis and neurodegeneration [1]. Interspecies differences in brain development, and insufficient data about duration and numbers of anesthetic exposures are also shortcomings of these animal models. Nonetheless, the consistent and reproducible adverse neurodegenerative and neurobehavioral effects in these models justify the intense investigation into whether the human fetus, infant, and young child could be affected by this problem.

\section{Anesthetic and Sedative Neurotoxicity in Infants, Children, and the Fetus}

Approximately 6 million children receive anesthesia annually in the US; with 2-3 million of these anesthetics in children $<36$ months of age, and 1.5 million in infants $<12$ months of age [23]. There were approximately 1,500 fetal interventions and surgeries in the US in 2014, according to the North American Fetal Therapy Network [24]. This is a growing population given the expanding numbers of fetal intervention programs and cases. Particularly concerning would be longer procedures where the mother receives general anesthesia with significant concentrations of volatile anesthetics to help maintain uterine quiescence and anesthetize both mother and fetus [25]. Significant levels of these GABAergic agents would be attained in the fetal brain, potentially placing the fetal brain at significant risk for neurodegenerative changes.

Effect of Anesthesia on the Developing Brain
Additionally, fetuses undergoing surgical procedures (e.g., diaphragmatic hernia, myelomeningocele) will often have repeated anesthetics in postnatal life.

In 2009, Wilder et al. [6] published the first large-scale retrospective study of anesthetic exposure under 4 years of age, and assessed the incidence of later behavioral, learning, or developmental problems at school age. With prolonged or repeated exposure to anesthesia, there was an approximately 2 -fold increase in the rate of identification of these problems compared to subjects with no anesthesia exposure. Since that time, a number of retrospective studies have been published with mixed results as to association of anesthetic exposure with later neurobehavioral and developmental problems [7]. Studies from Europe that make the diagnosis of learning problems based on standardized academic testing during school age have largely found no association with anesthetic exposure and these problems [26]. On the other hand, studies such as the Raine Cohort in Western Australia, where direct formal neurodevelopmental testing has been employed, have documented an increased risk of language problems in exposed subjects [27]. Stratmann et al. [28] utilized a unique recognition memory test administered at age $6-11$ years after general anesthesia at $<4$ years, and in anesthetic-exposed subjects documented a significant deficit in this domain. With several dozen retrospective cohort studies published, despite their lack of consistency, there is a signal that there may be a real problem with neurodevelopmental outcomes in anesthetic-exposed infants, particularly with prolonged or repeated exposures. Further retrospective studies are likely to be very limited in terms of new information about the real effects of anesthetic exposure. To date, there are no published studies of human fetal anesthetic exposure and neurodevelopmental outcomes.

Two clinical studies with superior study design have recently been published that provide critical new information about this important problem. The GAS Study (General Anesthesia vs. Spinal anesthesia) enrolled 722 infants $<60$ weeks' postconceptional age undergoing inguinal hernia repair in 28 centers in North America, Europe, Australia, and New Zealand [29]. Subjects were randomized to general anesthesia with sevoflurane versus spinal anesthesia with bupivacaine. The primary outcome of the study is full-scale intelligence quotient (IQ) at age 5 years, with a difference of 5 points ( 100 is the population norm) considered clinically and statistically significant. The secondary outcome was the Cognitive Score of the Bayley Scales of Infant and Toddler Development-III at age 2 years, again with a population norm of

Fetal Diagn Ther 2018;43:1-11 DOI: $10.1159 / 000475928$ 
100, with a difference between groups of 5 points being significant. At age 2 years, the Bayley-III scores for the Cognitive domain, as well as the Language and Motor domain, were essentially identical between groups. Because of a $20 \%$ crossover rate to general anesthesia in the spinal anesthetic group due to suboptimal operating conditions, the authors analyzed the results both by the intention-totreat, and actual treatment groups and found no differences. Approximately $11 \%$ of subjects in both groups underwent a subsequent general anesthetic before age 2 years. Mean anesthetic time was $54 \mathrm{~min}$, and both groups were identical overall as to baseline clinical and demographic characteristics. The primary outcome at 5 years will test a more extensive battery of neurocognitive domains, so the final outcome of the GAS Study is yet to be determined. The GAS Study is the first fully prospective, randomized controlled trial of anesthetic technique and neurodevelopmental outcome and as such has attained landmark status in addressing the problem.

The PANDA Study (Pediatric Anesthesia NeuroDevelopment Assessment) enrolled 105 sibling pairs; 1 sibling had anesthesia in the past at age 3 years or younger for inguinal hernia repair [30]. Median anesthetic duration was $80 \mathrm{~min}$, with a range of $20-240 \mathrm{~min}$. The other sibling was not exposed to anesthesia and was within 3 years in age of the exposed sibling. Both siblings returned at age 8-15 years for an extensive battery of neurocognitive testing. This innovative study design minimized genetic and socioeconomic differences between groups. The primary outcome was the full scale, verbal, and performance IQ. Scores between groups in these outcomes were virtually identical. Secondary tests of memory, language, attention, and executive function were also not different. There were some minor differences in behavior by parental questionnaire, but the effect (i.e., anesthesia worse than no anesthesia) was not consistent.

Both of these studies have important implications for the field of anesthetic neurotoxicity. They imply that a single, relatively brief exposure to anesthesia is not associated with an increased incidence of neurobehavioral adverse effects. Many investigators feel that the focus of this field of investigation should shift to prolonged or repeated exposures to anesthesia, or to the effect of anesthesia on vulnerable brains, i.e. the fetus, congenital heart disease infants, or infants with other complex neonatal surgical conditions such as diaphragmatic hernia. Additionally the effect of prolonged sedation, i.e. in critically ill infants in intensive care units, should be assessed in future research.

\section{Dexmedetomidine as a Neuroprotectant in Anesthetic Neurotoxicity}

Dexmedetomidine is a novel sedative/hypnotic agent that acts at central nervous system $\alpha_{2}$-adrenergic receptor binding sites as a highly selective agonist. Dexmedetomidine produces hypnosis and anxiolysis by binding presynaptic $\alpha_{2}$-receptors in the locus coeruleus in the brain, and analgesia by binding to $\alpha_{2}$-receptors in the spinal cord [31] (Table 1). It was approved by the US Food and Drug Administration (FDA) in 1999 for use as an intensive care unit sedative in ventilated adults, and a second indication was approved in 2007 for procedural sedation in spontaneously ventilating adults [32]. Dexmedetomidine is not US FDA labeled for use in patients under 18 years of age; however, it has attained widespread use in pediatric anesthesiology and critical care. It is utilized for postoperative sedation, as a component of total intravenous anesthesia regimens, for opioid-sparing in tonsillectomy, and also for premedication, procedural sedation, prevention of postoperative emergence agitation, and as a component of a balanced general anesthetic technique [33]. Among dexmedetomidine's desirable properties are its ability to maintain normal respiratory patterns, reduce the incidence of postcardiac surgical tachydysrhythmias [34], and reduce doses of volatile anesthetic agents and opioids when utilized as a component of a balanced anesthetic technique [33]. Dexmedetomidine has a significant body of research and clinical publication in children; a recent PubMed search revealed over 500 publications in children $0-18$ years, and 200 in children birth to 2 years of age.

Because dexmedetomidine has no interaction with either GABA or NMDA receptors, and because of its widespread use and familiarity in clinical pediatric medicine and surgery, it is an attractive agent for study in anesthetic neurotoxicity. Sanders and colleagues exposed neonatal rats to dexmedetomidine at significant concentrations and demonstrated no increase from baseline neuroapoptosis with dexmedetomidine alone [35]. They then exposed a different group to isoflurane and replicated a robust increase in neuroapoptosis after a 6-h exposure. When dexmedetomidine was added to the isoflurane exposure, there was a dose-dependent reduction in neuroapoptosis, down to the same baseline levels seen in control neonatal rats not exposed to any agent (Fig. 4). Importantly, in the survival cohorts of rats tested during adulthood for memory and spatial orientation, dexmedetomidine exposure alone resulted in no deficits compared to unexposed rats. Isoflurane exposure alone re-
6

Fetal Diagn Ther 2018;43:1-11

DOI: $10.1159 / 000475928$
Andropoulos 


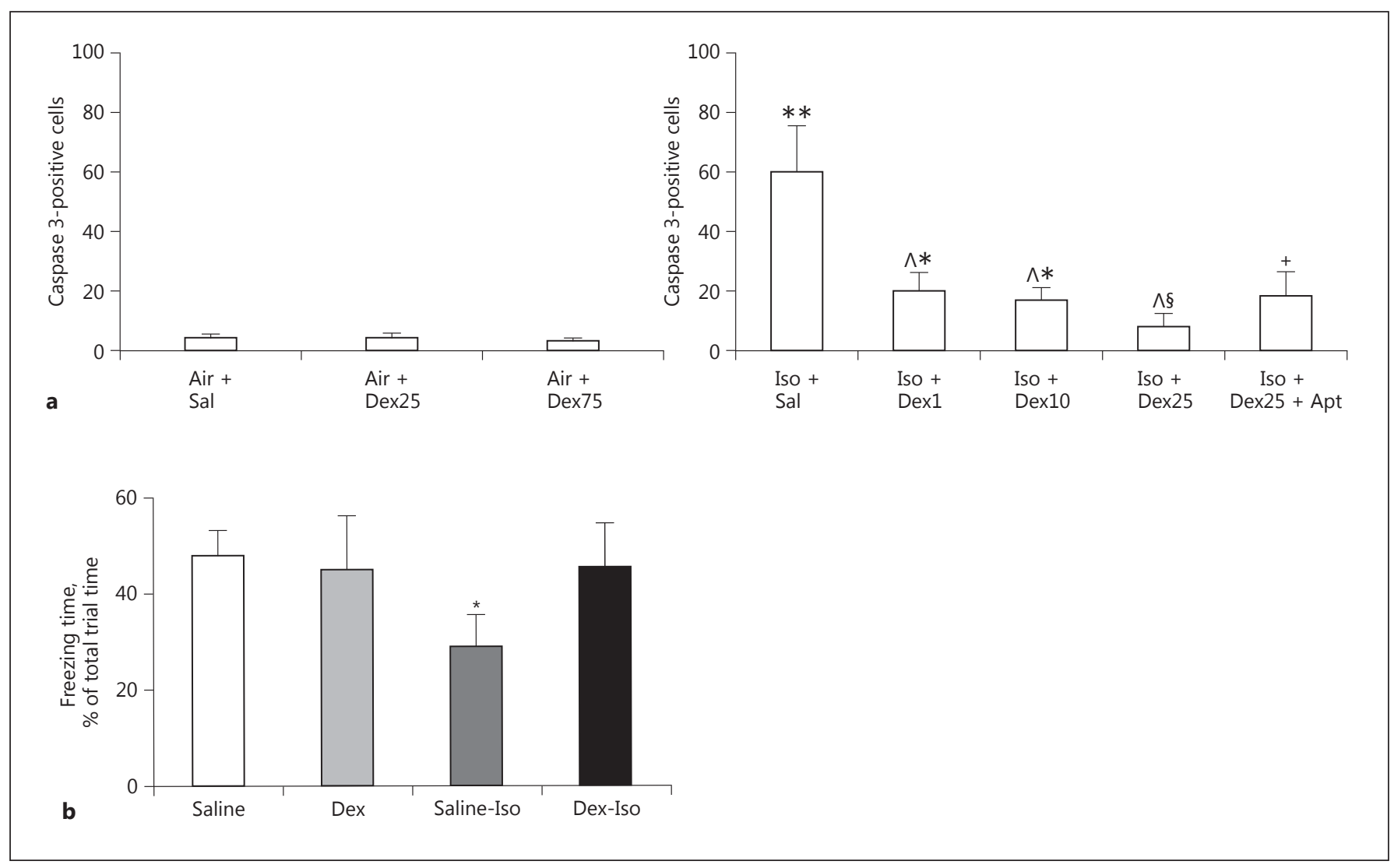

Fig. 4. Attenuation of isoflurane-induced neurodegeneration by dexmedetomidine in neonatal rats. a Neuroapoptosis in the hippocampus (caspase 3 staining). Left panel: left to right - exposure to air plus saline control, air plus dexmedetomidine $25 \mu \mathrm{g} / \mathrm{kg}$ intraperitoneally, and air plus dexmedetomidine $75 \mu \mathrm{g} / \mathrm{kg}$. There is no change in the level of neuroapoptosis from baseline. Right panel: left to right - exposure to isoflurane plus saline control, isoflurane plus dexmedetomidine $1 \mu \mathrm{g} / \mathrm{kg}$ intraperitoneally, isoflurane plus dexmedetomidine $10 \mu \mathrm{g} / \mathrm{kg}$, isoflurane plus dexmedetomidine $25 \mu \mathrm{g} / \mathrm{kg}$, and isoflurane plus dexmedetomidine $25 \mu \mathrm{g} / \mathrm{kg}$ plus atipamezole $\left(\alpha_{2}\right.$-receptor antagonist). ${ }^{*} p<0.05$ vs. air + saline; ${ }^{* *} p<0.01$ vs. air + saline; ${ }^{\wedge} p<0.001$ vs. isoflurane + saline; ${ }^{\circledR} p<$

sulted in a significant decrement in performance on these tests, as expected. When dexmedetomidine was added to isoflurane, performance on the tests was equal to baseline performance in unexposed animals. This study gave rise to the concept that dexmedetomidine alone did not cause neuroapoptosis, and when added to standard clinical doses of volatile anesthetic agents, could ameliorate both the acute neurodegenerative injury, and later neurobehavioral deficits. Since the Sanders paper in 2009, there have been 9 additional published studies in fetal or neonatal animal models assessing dexmedetomidine's effect on

Effect of Anesthesia on the Developing Brain
0.05 vs. isoflurane + dexmedetomidine $25 \mu \mathrm{g} / \mathrm{kg} ;{ }^{+} p<0.01 \mathrm{vs}$. isoflurane + saline. Dexmedetomidine provided dose-dependent reduction in caspase 3 staining for neuroapoptosis in the hippocampus, and cortex (not shown) and thalamus (not shown). Partial reversal of dexmedetomidine neuroprotection by the $\alpha_{2}$-antagonist atipamezole suggests at least partial mediation by this mechanism. b Cognitive function assessed by trace fear conditioning (freezing time; shorter time $=$ worse performance). ${ }^{*} p<0.05$ vs. other groups. Dexmedetomidine alone did not affect cognitive performance, and reversed the deficit in cognitive performance produced by isoflurane. Reproduced with permission from Sanders et al. [35].

neuroapoptosis. Of these 10 total studies, 8 demonstrate no neuroapoptosis, and in all 3 studies that conducted later neurobehavioral testing in surviving animals, dexmedetomidine ameliorated the deficits associated with isoflurane administration [19-22, 36-40] (Table 2). In a study by Pancaro et al. [40], dexmedetomidine at very high doses did result in neuroapoptosis in the sensory cortex and the thalamus. Liu et al. [39] exposed neonatal rat pups to increasing cumulative doses of dexmedetomidine delivered as 5 intraperitoneal injections over $6 \mathrm{~h}$, including 50,125, and $250 \mu \mathrm{g} / \mathrm{kg}$. The lower dose corre- 
Table 2. Fetal and neonatal studies of dexmedetomidine neurotoxicity

\begin{tabular}{|c|c|c|c|c|c|c|c|c|c|}
\hline $\begin{array}{l}\text { First author } \\
\text { [Ref.] }\end{array}$ & Species & $\begin{array}{l}\text { Stage of } \\
\text { gestation }\end{array}$ & $\begin{array}{l}\text { Additional } \\
\text { drugs }\end{array}$ & $\begin{array}{l}\text { Physiological } \\
\text { monitoring? }\end{array}$ & $\begin{array}{l}\text { DEX dosing, } \\
\mu \mathrm{g} / \mathrm{kg} \text {; duration }\end{array}$ & Brain regions & $\begin{array}{l}\text { Neuroapoptosis } \\
\text { from DEX? }\end{array}$ & $\begin{array}{l}\text { Ameliorate } \\
\text { 2nd drug } \\
\text { injury? }\end{array}$ & $\begin{array}{l}\text { Behavioral } \\
\text { testing/ } \\
\text { amelioration } \\
\text { from DEX? }\end{array}$ \\
\hline $\begin{array}{l}\text { Sanders } \\
{[35]}\end{array}$ & Rat & P7 neonatal & Isoflurane & $\begin{array}{l}\text { No - all } \\
\text { survived }\end{array}$ & $\begin{array}{l}\text { Up to } 75 \mathrm{IP} \text {; } \\
6 \mathrm{~h}\end{array}$ & $\begin{array}{l}\text { Cortex, hippocampus, } \\
\text { thalamus }\end{array}$ & No & Yes & Yes/yes \\
\hline $\begin{array}{l}\text { Sanders } \\
{[36]}\end{array}$ & Rat & P7 neonatal & Isoflurane & $\begin{array}{l}\text { No - all } \\
\text { survived }\end{array}$ & $\begin{array}{l}\text { Up to } 225 \mathrm{IP} \\
6 \mathrm{~h}\end{array}$ & Cortex & No & Yes - partial & No \\
\hline Liao [37] & Rat & P7 neonatal & Isoflurane & No & $\begin{array}{l}\text { Up to } 225 \mathrm{IP} \\
6 \mathrm{~h}\end{array}$ & Hippocampus & No & Yes - partial & No \\
\hline Koo [21] & Monkey & $\begin{array}{l}\text { Fetal: } 0.75 \\
\text { gestation }\end{array}$ & n.a. & Only HR, temp. & $\begin{array}{l}\text { Up to } 360 \mathrm{IV} \\
12 \mathrm{~h}\end{array}$ & Frontal cortex & No & n.a. & No \\
\hline $\begin{array}{l}\text { Olutoye } \\
\text { [22] }\end{array}$ & Sheep & $\begin{array}{l}\text { Fetal: } 0.9 \\
\text { gestation }\end{array}$ & Isoflurane & Yes & $2 \mathrm{IV} ; 1.2 \mathrm{~h}$ & $\begin{array}{l}\text { Cortex, } \\
\text { hippocampus }\end{array}$ & No & Yes & No \\
\hline $\operatorname{Li}[38]$ & Rat & P7 neonatal & Isoflurane & Yes & Up to $75 \mathrm{IP} ; 6 \mathrm{~h}$ & Hippocampus & No & & No \\
\hline Li [19] & Rat & $\begin{array}{l}\text { Prenatal day } 20 \\
(0.9 \text { gestation })\end{array}$ & Propofol & Yes & $10 \mathrm{IP} ; 6 \mathrm{~h}$ & Cortex, thalamus & No & Yes & Yes/yes \\
\hline Duan [20] & Rat & P7 neonatal & Ketamine & Only temp. & $75 \mathrm{SQ} ; 72 \mathrm{~h}$ & Hippocampus & No & Yes & Yes/yes \\
\hline $\begin{array}{l}\text { Pancaro } \\
{[40]}\end{array}$ & Rat & P7 neonatal & n.a. & No & $\begin{array}{l}\text { Up to } 270 \mathrm{SQ} \\
9 \mathrm{~h}\end{array}$ & $\begin{array}{l}\text { Sensory/limbic cortex/ } \\
\text { thalamus }\end{array}$ & $\begin{array}{l}\text { Yes (sensory } \\
\text { cortex/thalamus) } \\
\text { No (limbic cortex/ } \\
\text { thalamus) }\end{array}$ & n.a. & No \\
\hline Liu [39] & Rat & P7 neonatal & Ketamine & Yes - HR, $\mathrm{SpO}_{2}$ & $\begin{array}{l}50,125,250 \mathrm{IP} \\
6 \mathrm{~h}\end{array}$ & Somatosensory cortex & $\begin{array}{l}\text { Yes (somatosensory } \\
\text { cortex at high doses) }\end{array}$ & No & No \\
\hline
\end{tabular}

DEX, dexmedetomidine; P7, 7th postnatal day; IP, intraperitoneal; n.a., not applicable; HR, heart rate; temp., temperature; IV, intravenous; SQ, subcutaneous; SpO 2 , pulse oximeter saturation.

sponds to a clinically relevant dose, and the high dose is significantly supratherapeutic, producing plasma levels far in excess of the clinically relevant concentrations in humans. The 50 and $125 \mu \mathrm{g} / \mathrm{kg}$ doses did not produce neuroapoptosis that was greater than control levels; the $250 \mu \mathrm{g} / \mathrm{kg}$ dose significantly increased neuroapoptosis. The neurodegenerative effects of the high-dose dexmedetomidine were reversed by $\alpha_{1}$-receptor blocking agents, suggesting that the high doses have significant binding to this receptor, which is known to cause neurodegeneration. The authors concluded that human clinical doses should not be neurotoxic, and have the potential to be neuroprotective. The fetal and neonatal animal model studies of dexmedetomidine are summarized in Table 2.

Two fetal studies of dexmedetomidine deserve special mention. Olutoye et al. [22] studied 9 ovine fetuses at 118-120 days' gestation who underwent $2-3 \mathrm{~h}$ of isoflurane anesthesia for an animal model of fetal balloon tracheal occlusion. Two weeks later, the animals underwent $6 \mathrm{~h}$ of isoflurane anesthesia for balloon retrieval, and 5 of 9 fetuses also received dexmedetomidine. Isoflurane produced an increase in neuroapoptosis, particularly in the dentate gyrus; when dexmedetomidine was added, there was a decrease in apoptosis, although not quite to baseline control levels. This study demonstrated the feasibility of using the ovine large animal model for the study of fetal anesthetic neurotoxicity. The advantages of this model include the ability to carefully monitor hemodynamic changes in the fetus, and the ability to obtain plasma levels of dexmedetomidine, which are technically extremely difficult in neonatal rodent models. Finally, Koo et al. [21] studied 20 fetal cynomolgus monkeys at 120 days of gestation. Mothers were exposed to ketamine at high dose for $12 \mathrm{~h}$, or dexmedetomidine at low dose $(3 \mu \mathrm{g} / \mathrm{kg}$ loading dose, $3 \mu \mathrm{g} / \mathrm{kg} / \mathrm{h}$ for $12 \mathrm{~h}$ ) or high dose $(30 \mu \mathrm{g} / \mathrm{kg}$ loading dose, $30 \mu \mathrm{g} / \mathrm{kg} / \mathrm{h}$ for $12 \mathrm{~h}$ ). At $6 \mathrm{~h}$ after infusion, brain histochemistry in the frontal cortex was assessed; there was no increase over baseline neuroapoptosis with either lowor high-dose dexmedetomidine; by contrast, ketamine resulted in a 9-fold increase in neuroapoptosis.

The increasing body of evidence in fetal and neonatal animal models that dexmedetomidine does not cause neurodegenerative changes at clinical doses, and can ameliorate these changes caused by common anesthetics such as isoflurane, propofol, and ketamine, make it an attractive agent to study in clinical trials of anesthetic neurotoxicity.
$8 \quad$ Fetal Diagn Ther 2018;43:1-11 DOI: $10.1159 / 000475928$
Andropoulos 


\section{Dexmedetomidine Clinical Studies}

Two pilot studies of dexmedetomidine as a component of anesthetic technique are underway to determine the safety and feasibility of using the drug in significant doses, as the first step in planning future randomized controlled trials. The first is the T-REX (Toxicity of Remifentanil and dEXmedetomine) pilot study. [41]. Because opioids, and specifically remifentanil [42], have not been demonstrated to cause neuroapoptosis, this combination of drugs represents the most plausible approach to study in comparison to standard anesthetic technique, e.g. sevoflurane, to assess whether any differences in neurodevelopmental outcome exist. Because short anesthetics are less likely to be a problem in neurodevelopment, the T-REX pilot study is enrolling 601 - to 12-month-old infants undergoing lower abdominal or lower extremity surgery lasting $>120 \mathrm{~min}$, with the addition of a caudal block to provide analgesia in the surgical field. The primary outcome of the study is feasibility of the technique, defined as not needing to abandon the technique due to hemodynamic compromise (bradycardia, hypotension), or suboptimal surgical conditions due to patient movement. Safety of the regimen will be assessed as well. Sixty subjects are being enrolled in 11 centers in the US, Europe, Australia, and New Zealand. If $>90 \%$ of the subjects complete the protocol without abandonment, the technique will be deemed feasible. The pilot study will be preliminary data for the planning of a prospective, randomized, controlled trial of dexmedetomidine-remifentanil versus a standard anesthetic technique, i.e. sevoflurane. Neurodevelopmental follow-up would likely be similar to the GAS trial, with first assessment at age 2 years.

The second trial underway is "A Phase I Study of Dexmedetomidine Bolus and Infusion in Corrective Infant Cardiac Surgery: Safety and Pharmacokinetics" [43]. This study is enrolling 1160- to 6-month-old infants undergoing corrective cardiac surgery with cardiopulmonary bypass for the arterial switch operation of transposition of the great vessels, or repair of ventricular septal defect or tetralogy of Fallot. Using a dose escalation approach, dexmedetomidine is added to a standardized anesthetic consisting of fentanyl and isoflurane, and a standardized sedation regimen in the intensive care unit using opioids and benzodiazepines. Safety events, primarily junctional bradycardia, atrioventricular block, and hypotension, are assessed as the primary outcome. A pharmacokinetic model is being created, which will be validated in the second part of the study. As with the T-REX study, these data will be used as preliminary data for the planning of a pro-

Effect of Anesthesia on the Developing Brain spective, randomized, placebo-controlled trial of dexmedetomidine versus saline placebo, added to a standardized anesthetic and sedative regimen. The primary outcome will be neurodevelopmental outcome, likely at age 2 years.

If successfully conducted, these randomized trials will have an optimized study design in an appropriate population of infants undergoing prolonged anesthetics, and in the case of the congenital heart surgery patients, brains that are vulnerable to injury and adverse neurodevelopmental outcomes. Sufficient sample sizes would minimize bias due to preexisting comorbidity, or differences in socioeconomic or genetic factors.

\section{US FDA Drug Safety Communication}

In December 2016, the US FDA issued a Drug Safety Communication (DSC), warning that, "repeated or lengthy use of general anesthetic and sedation drugs during surgeries or procedures in children younger than 3 years or in pregnant women during their third trimester may affect the development of children's brains" [44]. "Lengthy" is defined as $>3 \mathrm{~h}$; this warning was issued because of FDA's review of the preclinical and clinical data, and has resulted in a labeling change to all common anesthetic drugs binding to GABA and NMDA receptors, including volatile anesthetic agents. The DSC directs anesthesiologists, surgeons, and other proceduralists to discuss with parents this potential effect, and whether the procedure can safely be postponed, the expected duration, and the need for repeat anesthetics. This warning clearly has implications for fetal interventions and young children, and was issued by the FDA without new or concerning evidence in humans [45]. Nonetheless, the problem of potential anesthetic neurotoxicity assumes even greater urgency with the issuing of the FDA warning. The warning also states, "...additional high-quality research is needed to investigate the effects of repeated and prolonged anesthesia exposures in children, including vulnerable populations" [44].

\section{Conclusion}

The potential for anesthetic neurotoxicity in the neonate, young infant, and fetus is the most pressing question facing the field of pediatric and fetal anesthesia [46]. The very rapid development of the fetal brain potentially makes this the patient group most vulnerable to neuro-

Fetal Diagn Ther 2018;43:1-11

DOI: $10.1159 / 000475928$ 
toxicity from anesthesia. The increasing number of fetal interventions requiring anesthesia make this a very important field of research inquiry. In addition, the two recent well-designed "negative" studies of brief, single anesthetic exposure during young childhood should shift the clinical research emphasis to patients undergoing prolonged procedures, or those with known neurodevelopmental vulnerability, e.g. congenital heart disease, other complex neonatal surgeries, and the fetus.

\section{References}

1 Rappaport BA, Suresh S, Hertz S, Evers AS, Orser BA: Anesthetic neurotoxicity - clinical implications of animal models. N Engl J Med 2015;372:796-797.

2 Ikonomidou C, Bosch F, Miksa M, Bittigau P, Vöckler J, Dikranian K, Tenkova TI, Stefovska V, Turski L, Olney JW: Blockade of NMDA receptors and apoptotic neurodegeneration in the developing brain. Science 1999; 283:70-74.

3 Jevtovic-Todorovic V, Hartman RE, Izumi Y, Benshoff ND, Dikranian K, Zorumski CF, Olney JW, Wozniak DF: Early exposure to common anesthetic agents causes widespread neurodegeneration in the developing rat brain and persistent learning deficits. J Neurosci 2003;23:876-882.

4 Paule MG, Li M, Allen RR, Liu F, Zou X, Hotchkiss C, Hanig JP, Patterson TA, Slikker W Jr, Wang C: Ketamine anesthesia during the first week of life can cause long-lasting cognitive deficits in rhesus monkeys. Neurotoxicol Teratol 2011;33:220-230.

5 Creeley CE, Dikranian KT, Dissen GA, Back SA, Olney JW, Brambrink AM: Isofluraneinduced apoptosis of neurons and oligodendrocytes in the fetal rhesus macaque brain. Anesthesiology 2014;120:626-638.

6 Wilder RT, Flick RP, Sprung J, Katusic SK, Barbaresi WJ, Mickelson C, Gleich SJ, Schroeder DR, Weaver AL, Warner DO: Early exposure to anesthesia and learning disabilities in a population-based birth cohort. Anesthesiology 2009;110:796-804.

7 DiMaggio C, Sun LS, Ing C, Li G: Pediatric anesthesia and neurodevelopmental impairments: a Bayesian meta-analysis. J Neurosurg Anesthesiol 2012;24:376-381.

8 Psaty BM, Platt R, Altman RB: Neurotoxicity of generic anesthesia agents in infants and children: an orphan research question in search of a sponsor. JAMA 2015;313:15151516.

9 Lin EP, Soriano SG, Loepke AW: Anesthetic neurotoxicity. Anesthesiol Clin 2014;32:133155.

10 Olsen EA, Brambrink AM: Anesthetic neurotoxicity in the newborn and infant. Curr Opin Anaesthesiol 2013;26:535-542.

11 Davidson A, Flick RP: Neurodevelopmental implications of the use of sedation and analgesia in neonates. Clin Perinatol 2013;40: 559-573.
12 Davidson AJ, Becke K, de Graaff J, Giribaldi G, Habre W, Hansen T, Hunt RW, Ing C, Loepke A, McCann ME, Ormond GD, Pini Prato A, Salvo I, Sun L, Vutskits L, Walker S, Disma N: Anesthesia and the developing brain: a way forward for clinical research. Paediatr Anaesth 2015;25:447-452.

13 Tymofiyeva O, Hess CP, Xu D, Barkovich AJ: Structural MRI connectome in development: challenges of the changing brain. Br J Radiol 2014;87:20140086.

14 Huang H, Vasung L: Gaining insight of fetal brain development with diffusion MRI and histology. Int J Dev Neurosci 2014;32:11-22.

15 Sanders RD, Hassell J, Davidson AJ, Robertson NJ, Ma D: Impact of anaesthetics and surgery on neurodevelopment: an update. $\mathrm{Br}$ Anaesth 2013;110(suppl 1):i53-i72.

16 Istaphanous GK, Ward CG, Nan X, Hughes EA, McCann JC, McAuliffe JJ, Danzer SC, Loepke AW: Characterization and quantification of isoflurane-induced developmental apoptotic cell death in mouse cerebral cortex. Anesth Analg 2013;116:845-854.

17 Istaphanous GK, Ward CG, Loepke AW: The impact of the perioperative period on neurocognitive development, with a focus on pharmacological concerns. Best Pract Res Clin Anaesthesiol 2010;24:433-449.

18 Coleman K, Robertson ND, Dissen GA, Neuringer MD, Martin LD, Carlson VC, Kroenke C, Fair D, Brambrink AM: Isoflurane anesthesia has long-term consequences on motor and behavioral development in infant rhesus macaques. Anesthesiology 2017;126:74-84.

$19 \mathrm{Li}$ J, Xiong M, Nadavaluru PR, Zuo W, Ye JH, Eloy JD, Bekker A: Dexmedetomidine attenuates neurotoxicity induced by prenatal propofol exposure. J Neurosurg Anesthesiol 2016; 28:51-64.

20 Duan X, Li Y, Zhou C, Huang L, Dong Z: Dexmedetomidine provides neuroprotection: impact on ketamine-induced neuroapoptosis in the developing rat brain. Acta Anaesthesiol Scand 2014;58:1121-1126.

21 Koo E, Oshodi T, Meschter C, Ebrahimnejad A, Dong G: Neurotoxic effects of dexmedetomidine in fetal cynomolgus monkey brains. J Toxicol Sci 2014;39:251-262.

22 Olutoye OA, Lazar DA, Akinkuotu AC, Adesina A, Olutoye OO: Potential of the ovine brain as a model for anesthesia-induced neuroapoptosis. Pediatr Surg Int 2015;31:865869.
23 Sun L: Early childhood general anaesthesia exposure and neurocognitive development. Br J Anaesth 2010;105(suppl 1):i61-i68.

24 North American Fetal Therapy Network. https://www.naftnet.org/.

25 Rollins MD, Rosen MA: Anesthesia for fetal intervention and surgery; in Gregory GA, Andropoulos DB (eds): Pediatric Anesthesia, ed 5. Oxford, Wiley-Blackwell, 2012, pp 444-474.

26 Hansen TG, Pedersen JK, Henneberg SW, Pedersen DA, Murray JC, Morton NS, Christensen K: Academic performance in adolescence after inguinal hernia repair in infancy: a nationwide cohort study. Anesthesiology 2011;114:1076-1085.

27 Ing C, DiMaggio C, Whitehouse A, Hegarty MK, Brady J, von Ungern-Sternberg BS, Davidson A, Wood AJ, Li G, Sun LS: Long-term differences in language and cognitive function after childhood exposure to anesthesia. Pediatrics 2012;130:e476-e485.

28 Stratmann G, Lee J, Sall JW, Lee BH, Alvi RS, Shih J, Rowe AM, Ramage TM, Chang FL, Alexander TG, Lempert DK, Lin N, Siu KH, Elphick SA, Wong A, Schnair CI, Vu AF, Chan JT, Zai H, Wong MK, Anthony AM, Barbour KC, BenTzur D, Kazarian NE, Lee JY, Shen JR, Liu E, Behniwal GS, Lammers CR, Quinones Z, Aggarwal A, Cedars E, Yonelinas AP, Ghetti S: Effect of general anesthesia in infancy on long-term recognition memory in humans and rats. Neuropsychopharmacology 2014;39:2275-2287.

29 Davidson AJ, Disma N, de Graaff JC, Withington DE, Dorris L, Bell G, Stargatt R, Bellinger DC, Schuster T, Arnup SJ, Hardy P, Hunt RW, Takagi MJ, Giribaldi G, Hartmann PL, Salvo I, Morton NS, von Ungern Sternberg BS, Locatelli BG, Wilton N, Lynn A, Thomas JJ, Polaner D, Bagshaw O, Szmuk P, Absalom AR, Frawley G, Berde C, Ormond GD, Marmor J, McCann ME; GAS consortium: Neurodevelopmental outcome at 2 years of age after general anaesthesia and awake-regional anaesthesia in infancy (GAS): an international multicentre, randomised controlled trial. Lancet 2016;387:239-250.

30 Sun LS, Li G, Miller TL, Salorio C, Byrne MW, Bellinger DC, Ing C, Park R, Radcliffe J, Hays SR, DiMaggio CJ, Cooper TJ, Rauh V, Maxwell LG, Youn A, McGowan FX: Association between a single general anesthesia exposure before age 36 months and neurocognitive outcomes in later childhood. JAMA 2016;315: 2312-2320. 
31 Su F, Nicolson SC, Gastonguay MR, Barrett JS, Adamson PC, Kang DS, Godinez RI, Zuppa AF: Population pharmacokinetics of dexmedetomidine in infants after open heart surgery. Anesth Analg 2010;110:1383-1392.

32 Precedex $^{\mathrm{TM}}$ Prescribing Information. https:// www.hospira.com/en/images/EN-4271_ tcm81-92504.pdf.

33 Mahmoud M, Mason KP: Dexmedetomidine: review, update, and future considerations of paediatric perioperative and periprocedural applications and limitations. $\mathrm{Br} \mathrm{J}$ Anaesth 2015;115:171-182.

34 Chrysostomou C, Sanchez-de-Toledo J, Wearden P, Jooste EH, Lichtenstein SE, Callahan PM, Suresh T, O’Malley E, Shiderly D, Haney J, Yoshida M, Orr R, Munoz R, Morell VO: Perioperative use of dexmedetomidine is associated with decreased incidence of ventricular and supraventricular tachyarrhythmias after congenital cardiac operations. Ann Thorac Surg 2011;92:964-972.

35 Sanders RD, Xu J, Shu Y, Januszewski A, Halder S, Fidalgo A, Sun P, Hossain M, Ma D, Maze M: Dexmedetomidine attenuates isoflurane-induced neurocognitive impairment in neonatal rats. Anesthesiology 2009;110: 1077-1085.
36 Sanders RD, Sun P, Patel S, Li M, Maze M, Ma D: Dexmedetomidine provides cortical neuroprotection: impact on anaesthetic-induced neuroapoptosis in the rat developing brain. Acta Anaesthesiol Scand 2010;54:710-716.

37 Liao Z, Cao D, Han X, Liu C, Peng J, Zuo Z, Wang F, Li Y: Both JNK and P38 MAPK pathways participate in the protection by dexmedetomidine against isoflurane-induced neuroapoptosis in the hippocampus of neonatal rats. Brain Res Bull 2014;107:69-78.

38 Li Y, Zeng M, Chen W, Liu C, Wnag F, Han F, Zuo Z, Peng S: Dexmedetomidine reduces isoflurane-induced neuroapoptosis partly by preserving PI3K/Akt pathway in the hippocampus of neonatal rats. PLoS One 2014; e93639.

39 Liu JR, Yuki K, Baek C, Han XH, Soriano SG: Dexmedetomidine-induced neuroapoptosis is dependent on its cumulative dose. Anesth Analg 2016;123:1008-1017.

40 Pancaro C, Segal BS, Sikes RW, Almeer Z, Schumann R, Azocar RJ, Marchand JE: Dexmedetomidine and ketamine show distinct patterns of cell degeneration and apoptosis in the developing rat neonatal brain. J Matern Fetal Neonatal Med 2016;29:3827-3833.

41 The T REX pilot study: a study to investigate the use of an alternative anaesthetic in infants. ClinicalTrials.gov. https://clinicaltrials.gov/ ct $2 / \mathrm{show} / \mathrm{NCT} 02353182$ ? t e r m = TREX\&rank=4; NCT02353182.
42 Tourrel F, de Lendeu PK, Abily-Donval L, Chollat C, Marret S, Dufrasne F, Compagnon P, Ramdani Y, Dureuil B, Laudenbach V, Gonzalez BJ, Jégou S: The antiapoptotic effect of remifentanil on the immature mouse brain: an ex vivo study. Anesth Analg 2014;118: 1041-1051.

43 A phase I study of dexmedetomidine bolus and infusion in corrective infant cardiac surgery: safety and pharmacokinetics. ClinicalTrials.gov. https://clinicaltrials.gov/ct2/ show/NCT01915277?term=andropoulos\&ra $\mathrm{nk}=2$; NCT01915277.

44 US Food and Drug Administration Website: http://www.fda.gov/Drugs/DrugSafety/ ucm532356.htm; accessed December 23, 2016.

45 Andropoulos DB, Greene MF: Anesthesia and developing brains: implications of the FDA warning. N Engl J Med 2017;376:905907.

46 Boney O, Bell M, Bell N, Conquest A, Cumbers M, Drake S, Galsworthy M, Gath J, Grocott MP, Harris E, Howell S, Ingold A, Nathanson MH, Pinkney T, Metcalf L: Identifying research priorities in anaesthesia and perioperative care: final report of the joint National Institute of Academic Anaesthesia/ James Lind Alliance Research Priority Setting Partnership. BMJ Open 2015;5:e10006.
Effect of Anesthesia on the Developing Brain
Fetal Diagn Ther 2018;43:1-11

DOI: $10.1159 / 000475928$ 